pandémica da COVID-19, o 14. Encontro de Química Física revelou-se um excelente fórum de discussão e partilha de conhecimento científico. 0 empenhamento de todos os elementos da Comissão Científica, a quem ficamos em dívida, foi fundamental para o sucesso deste evento. A Comissão Organizadora agradece à Direção e ao Secretariado da SPQ todo o apoio prestado e aos patrocinadores pelo suporte financeiro. Um agradecimento especial é devido ao Departamento de Química da Universidade de Coimbra e ao Centro de Química de Coimbra pelo suporte institucional. Finalmente, estamos gratos a todos os participantes pela sua contribuição e entusiasmo!

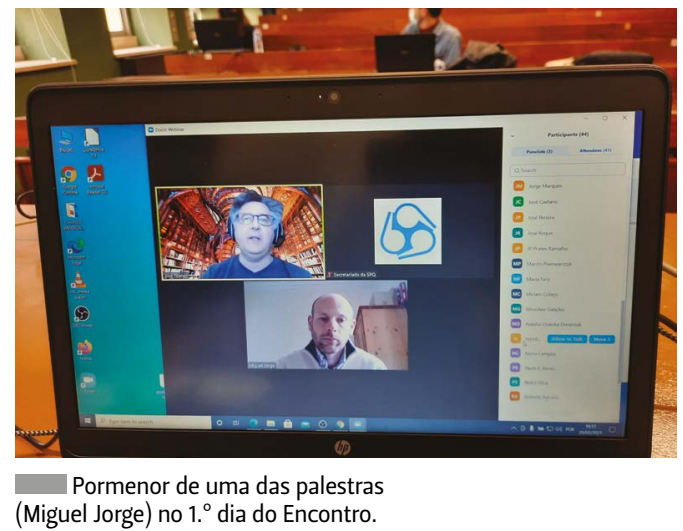

(Miguel Jorge) no $1 .^{\circ}$ dia do Encontro.

\section{Prémio Ferreira da Silva 2020 e Medalha Vicente de Seabra 2020}

O júri do Prémio Ferreira da Silva 2020 e da Medalha Vicente de Seabra 2020 reuniu a 7 de abril de 2021, e atribuiu por unanimidade ambas as distinções. 0 Prémio Ferreira da Silva 2020 distinguiu Mário Nuno Berberan e Santos, Professor Catedrático e líder do Grupo de Bioespectroscopia e Interfaces no Instituto de Bioengenharia e Biociências, Instituto Superior Técnico, Universidade de Lisboa, Presidente da SPQ entre 2010 e 2013. A Medalha Vicente de Seabra 2020 foi atribuída a Gonçalo Bernardes, líder do Grupo de Biologia Química e Biotecnologia Farmacêutica no Instituto de Medicina Molecular, Faculdade de Medicina, Universidade de Lisboa.

Os interesses científicos do Professor Mário Nuno Berberan e Santos incluem a luminescência de sistemas nanoestruturados, em especial fulerenos e outros compostos de carbono, e a dinâmica de processos envolvendo estados eletrónicos excitados, nomeadamente a fluorescência retardada por ativação térmica (TADF) e respetivas aplicações como sondas de oxigénio e de temperatura e OLEDs.

A investigação do Doutor Gonçalo Bernardes está focada em terapêuticas direcionadas ao tratamento do cancro, e desenvolvimento de ferramentas para a modificação de proteínas específicas associadas a várias doenças, incluindo a doença de Parkinson.

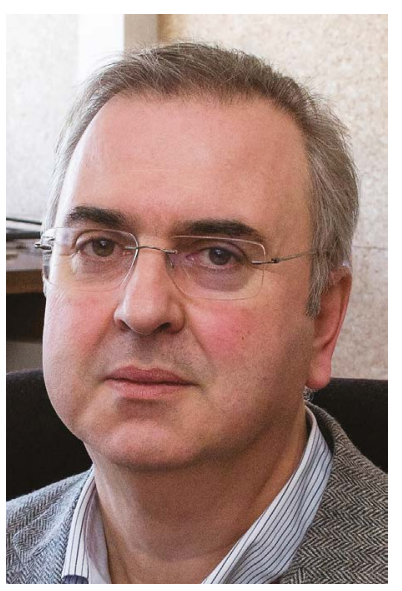

Mário Nuno Berberan e Santos

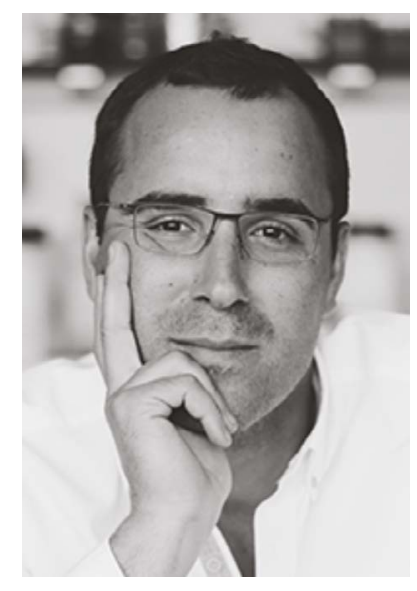

Gonçalo Bernardes
Os prémios serão entregues durante o XXVII Encontro Nacional da SPQ, que se realizará em Braga de 14 a 16 de julho de 2021. Durante o evento, os premiados darão uma palestra sobre os mais recentes avanços da sua investigação.

As listas de todos os vencedores dos Prémios Ferreira da Silva e Vicente de Seabra podem ser consultadas em spq.pt/premios/ferreira-silva/lista e spq. pt/premios/vicente-seabra/lista.

\section{Bruno Machado}

brunofm@fe.up.pt 